\title{
Endoscopic Retrograde Cholangiopancreatography with Intraductal Ultrasound in Pregnancy without the Use of Radiation
}

\author{
Anuj Datta ${ }^{* 1}$, Viktor Eysselein ${ }^{1}$, Michael Fleischman ${ }^{1}$, Sonya Reicher ${ }^{1}$, Inder Singh $^{1}$, Ashwin Ashok ${ }^{1}$ and Kelsey Chen $^{2}$ \\ ${ }^{1}$ Division of Gastroenterology/Hepatology, Harbor-UCLA Medical Center, Torrance, CA 90502, USA \\ ${ }^{2}$ Department of Internal Medicine, Harbor-UCLA Medical Center, Torrance, CA 90502, USA
}

\begin{abstract}
Goals and background: Biliary disease in pregnancy presents unique challenges. Conservative treatment is associated with recurrent symptoms, and the use of radiographic imaging is limited because of the possibility of fetal exposure. The aim of our study was to evaluate the use of intraductal ultrasound (IDUS) in nonradiation ERCP (ERCP-NR) to treat pregnant women with symptomatic choledocholithiasis or gallstone pancreatitis.

Study: From 2008 to 2014, we retrospectively identified ten pregnant patients at our urban safety net teaching hospital who were treated with IDUS-guided ERCP for symptomatic choledocholithiasis or gallstone pancreatitis. The cases were compiled to provide a descriptive review of ERCP with IDUS.

Results: Of 10 pregnant patients who underwent ERCP, eight patients had prior EUS demonstrating common bile duct stones, and two had gallstone pancreatitis. There were no immediate procedure-related adverse events and no patients required a repeat procedure. All ERCP procedures were successful for removing the bile duct stones and providing symptomatic relief. There were no known immediate or long-term procedure-related adverse events in the infants.

Conclusions: IDUS-guided ERCP-NR provides appropriate biliary imaging without fetal radiation exposure and can be safely and successfully performed in pregnancy.
\end{abstract}

\section{Introduction}

Hormonal changes and weight gain are thought to be predisposing factors to gallstone formation in pregnant woman. Gallstones affect one in 1200 pregnant women, one-third of whom may become symptomatic [1]. Cholecystectomy within the first trimester has been associated with a spontaneous abortion rate of $12 \%$, and cholecystectomy with common bile duct (CBD) exploration has been associated with a maternal mortality rate of $15 \%$ and fetal loss rate of $60 \%$ [2].

Endoscopic retrograde cholangiopancreatography (ERCP) with sphincterotomy is considered the most ideal intervention to date for management of biliary stone disease; however, the radiation exposure from ERCP with fluoroscopic guidance may present a risk to the developing fetus.

Guidelines state that radiation exposure should not exceed $1 \mathrm{mSv}$ in the first trimester and $5 \mathrm{mSv}$ over the entire gestation $[1,3]$.

An attempt to quantify fetal radiation exposure in pregnant patients undergoing ERCP found that in 35 therapeutic ERCPs, the estimated exposure was $<0.1-0.5 \mathrm{mSv}$, which is far less than the $5 \mathrm{mSv}$ maximum, with only two births were complicated by pre-term delivery [4]. The above study concluded that ERCP with modified techniques is safe in pregnancy, but a rebuttal contended that those conclusions lacked adequate support [5].

Few studies of fetal radiation exposure exist in the literature and often have small cohorts. For example, one retrospective study measured mean fluoroscopy time and found that despite a mean of 3.8 minutes, 15 of 16 patients had full-term pregnancies [3].

Adequate experimental evidence to support the use of nonradiation ERCP (ERCP-NR) during pregnancy is also lacking, and several alternative approaches have been attempted with the goal of reducing radiation exposure to the fetus. Multi-step methods include conservative management followed by intervention in the second trimester [6], a two-step endoscopic approach [1], and pre-procedure ultrasound or magnetic resonance cholangiopancreatography (MRCP) $[7,8]$.

With limited data, it appears that relatively few adverse events are associated with the multi-step approach. Single-step alternatives to ERCP with fluoroscopy have also been attempted and include ultrasound-guided, endoscopic ultrasound (EUS)-guided and per-oral cholangioscopy-guided ERCP. Same-session EUS provides information on size, location, and number of stones to guide ERCP and confirm stone clearance without the use of fluoroscopy. Intraductal ultrasound (IDUS) provides a way of assuring bile duct access and complete stone clearance during ERCP.

Our study evaluates the role of IDUS-guided ERCP-NR with the aid of EUS in the management of pregnant women with symptomatic choledocholithiasis or gallstone pancreatitis. To our knowledge, this is the only study using IDUS and captures one of the larger study populations of pregnant women to date.

Correspondence to: Dr. Anuj Datta, Division of Gastroenterology/Hepatology, Harbor-UCLA Medical Center, Torrance, CA 90502, USA, Tel: (310) 222-2475; E-mail: adatta@dhs.lacounty.gov

Key words: choledocholithiasis, endoscopic retrograde cholangiopancreatography, endosonography, fluoroscopy, pregnancy

Received: April 12, 2016; Accepted: May 05, 2016; Published: May 10, 2016 


\section{Materials and methods}

After obtaining Institutional Review Board approval, the endoscopic procedure database was retrospectively reviewed for pregnant patients 18 years and older undergoing ERCP-NR from January 2008 to August 2014 at our urban safety net hospital. Data on patient demographics, ERCP indications, presenting symptoms, procedural aspects, and maternal and fetal outcomes were collected.

The indication for therapeutic ERCP was symptomatic choledocholithiasis in eight patients and gallstone pancreatitis in two patients. Same-session EUS was performed with a radial array echoendoscope (Olympus Inc., UME160) prior to ERCP in eight of the ten patients to determine the presence or absence of extrahepatic duct stones. The remaining two patients had undergone laparoscopic cholecystectomy with intraoperative cholangiography significant for common bile duct stones. Deep selective biliary cannulation was accomplished with a sphinctertome and bile duct access was confirmed by aspiration of bile. IDUS $20 \mathrm{MHz}$ mini-EUS probe (Olympus, Inc., UMG2029R) was then introduced over the wire into the duct in order to confirm wire position in the CBD and estimate the distance needed for balloon advancement above the stone. When a guidewire was needed, a 0.035 inch numerically scored wire via an Ultratome (Boston Scientific, Boston, MA, USA) or a 0.025 inch numerically scored wire via a Jag 39 (Boston Scientific, Boston, MA, USA) was used to monitor the length of the wire advancement into the bile duct. Biliary sphincterotomy using ERBE endocut (ERBE USA Inc., Marietta, GA, USA) was performed, followed by stone extraction using a balloon catheter. The IDUS probe was then reintroduced to confirm stone clearance. A biliary stent was placed when indicated. No fluoroscopy was used in any patients.

\section{Results}

Patient characteristics are shown in Table 1. The mean age of the patients was 25.8 years old (range 19-37). Four were Hispanic, four were white, and two were black. The average gestational age was 12 weeks (range 4-33 weeks), with six patients in the first trimester of pregnancy, three in the second, and one in the third. Eight of the patients had symptomatic choledocholithiasis, and two had gallstone pancreatitis. All of the patients presented with abdominal pain, and five presented with nausea and vomiting. All of patients had abnormal laboratory values including elevated AST and total bilirubin. In addition, nine of ten had elevated ALT, eight had elevated alkaline phosphatase, one had elevated white count, and one had elevated lipase (Table 2).

Of the eight patients who underwent pre-procedure EUS, six were found to have a dilated CBD. Six were also found to have a bile duct stone on EUS, and one was found to have a gallbladder in situ with stones.

Based on the ASGE practice standards, seven patients were classified as high risk and three as intermediate risk for choledocholithiasis [9]. $70 \%$ had a high suspicion for bile duct stone, and $30 \%$ had intermediate suspicion. Procedural outcomes are shown in Table 3. Sphincterotomy was performed in all patients except one who had a previous biliary sphincterotomy. Stenting was performed in two patients. The average procedure time was 74.9 minutes, ranging from 23 to 196 minutes.

There were no immediate or long-term procedure-related adverse events and no patients required a repeat procedure. All procedures were successful for removing the bile duct stones and providing symptomatic relief; jaundice resolved in all cases.

With regard to fetal outcomes, two patients electively terminated their pregnancies. One infant was born via pre-term Cesarean section at 36 weeks with no further adverse events. One infant was delivered at full term without adverse events, and one infant was delivered at 40 weeks. Four patients were lost to follow-up, and one is pending delivery; the outcomes of their pregnancies are unknown. There were no known immediate or long-term procedure-related adverse events in the infants. No known fetal adverse events were reported.

\section{Discussion}

All patients in our study presented symptomatically for choledocholithiasis or gallstone pancreatitis with corresponding laboratory abnormalities and had high clinical suspicion for bile duct stones, confirmed by pre-procedure imaging. All patients subsequently underwent IDUS-guided ERCP-NR with sphincterotomy and/or stenting with no procedural or post-procedural adverse events.

The use of IDUS allowed for visualization of the CBD, confirmation of wire position within the CBD vs. cystic duct, and estimation of the

Table 1. Patient characteristics.

\begin{tabular}{|c|c|c|c|c|c|}
\hline Patients & Age & Gestation (weeks) & Symptoms & Suspicion for bile duct stone & Indication \\
\hline 1 & 21 & 6 & $\begin{array}{l}\text { Abdominal pain, } \\
\text { Nausea/Vomiting }\end{array}$ & Intermediate & $\mathrm{s} / \mathrm{p}$ lap cholecystectomy with $+\mathrm{IOC}$ \\
\hline 2 & 25 & 10 & Abdominal pain & High & Gallstone pancreatitis \\
\hline 3 & 27 & 6 & $\begin{array}{l}\text { Abdominal pain, } \\
\text { Nausea/Vomiting }\end{array}$ & High & Choledocholithiasis \\
\hline 4 & 21 & 14 & Abdominal pain & Intermediate & Choledocholithiasis \\
\hline 5 & 21 & 16 & $\begin{array}{l}\text { Abdominal pain, } \\
\text { Nausea/Vomiting }\end{array}$ & High & Choledocholithiasis \\
\hline 6 & 19 & 4 & Abdominal pain & High & Choledocholithiasis \\
\hline 7 & 37 & 8 & $\begin{array}{l}\text { Abdominal pain, } \\
\text { Nausea/Vomiting }\end{array}$ & Intermediate & $\mathrm{s} / \mathrm{p}$ lap cholecystectomy with $+\mathrm{IOC}$ \\
\hline 8 & 27 & 13 & Abdominal pain & High & $\mathrm{s} / \mathrm{p}$ lap cholecystectomy with $+\mathrm{IOC}$ \\
\hline 9 & 33 & 33 & Abdominal pain & High & Gallstone pancreatitis, Cholecystitis \\
\hline 10 & 27 & 6 & $\begin{array}{l}\text { Abdominal pain, } \\
\text { Nausea/Vomiting }\end{array}$ & High & Choledocholithiasis \\
\hline Summary & $\begin{array}{l}\text { Median } 25.8 \text { years old } \\
\quad \text { (range 19-37) }\end{array}$ & 12 weeks (range 4-33) & & $\begin{array}{c}\text { High } 70 \% \\
\text { Intermediate } 30 \%\end{array}$ & \\
\hline
\end{tabular}


Table 2. Laboratory values.

\begin{tabular}{|c|c|c|c|c|c|c|}
\hline Patients & AST & ALT & Alk Phos & T Bili & WBC & Lipase \\
\hline 1 & 270 & 219 & 92 & 1.5 & 8.6 & 17 \\
\hline 2 & 180 & 334 & 251 & 6.7 & 9.2 & 381 \\
\hline 3 & 195 & 327 & 374 & 5.3 & 6.6 & NA \\
\hline 4 & 63 & 235 & 172 & 3.6 & 8.1 & 19 \\
\hline 5 & 58 & 50 & 69 & 1.9 & 7.4 & 26 \\
\hline 6 & 270 & 478 & 206 & 5.6 & 9.5 & 28 \\
\hline 7 & 249 & 468 & 274 & 3.7 & 7.3 & 17 \\
\hline 8 & 63 & 73 & 208 & 3 & 6.1 & 28 \\
\hline 9 & 92 & 353 & 282 & 2 & 10.6 & 65 \\
\hline 10 & 62 & 172 & 204 & 7.9 & 9.3 & 19 \\
\hline
\end{tabular}

Legend: AST: Aspartate Transaminase, ALT: Alanine Transaminase, Alk Phos: Alkaline Phosphatase, T Bili: Total Bilirubin, WBC: White Blood Cell count

Table 3. Procedural outcomes.

\begin{tabular}{|c|c|c|c|c|c|c|c|c|}
\hline Patients & $\begin{array}{l}\text { CBD } \\
(\mathrm{mm})\end{array}$ & $\begin{array}{l}\text { Bile Duct } \\
\text { Stone }\end{array}$ & $\begin{array}{l}\text { Gallbladder in situ with } \\
\text { stones }\end{array}$ & Procedure & $\begin{array}{l}\text { Procedure Duration } \\
\text { (EUS + ERCP, min) }\end{array}$ & Sphincterotomy $(\mathbf{Y} / \mathbf{N})$ & Stent $(\mathbf{Y} / \mathbf{N})$ & Complications \\
\hline 1 & NA & $\mathrm{Y}$ & $\mathrm{N}$ & ERCP/IDUS & 23 & $\mathrm{Y}$ & $\mathrm{N}$ & None \\
\hline 2 & NA & $\mathrm{N}$ & $\mathrm{Y}$ & EUS/ERCP/IDUS & 29 & $\mathrm{Y}$ & $\mathrm{N}$ & None \\
\hline 3 & 6.9 & $\mathrm{Y}$ & $\mathrm{N}$ & EUS/ERCP/IDUS & 42 & $\mathrm{Y}$ & $\mathrm{N}$ & None \\
\hline 4 & 2 & $\mathrm{~N}$ & $\mathrm{~N}$ & EUS/ERCP/IDUS & 40 & $\mathrm{~N}$ & $\mathrm{~N}$ & None \\
\hline 5 & 6.4 & $\mathrm{~N}$ & $\mathrm{~N}$ & EUS/ERCP/IDUS & 40 & $\mathrm{Y}$ & $\mathrm{Y}$ & None \\
\hline 6 & 15 & $\mathrm{Y}$ & $\mathrm{N}$ & EUS/ERCP/IDUS & 63 & $\mathrm{Y}$ & $\mathrm{Y}$ & None \\
\hline 7 & NA & $\mathrm{Y}$ & $\mathrm{N}$ & ERCP/IDUS & 115 & $\mathrm{Y}$ & $\mathrm{N}$ & None \\
\hline 8 & NA & $\mathrm{Y}$ & $\mathrm{N}$ & EUS/ERCP/IDUS & 196 & $\mathrm{Y}$ & $\mathrm{N}$ & None \\
\hline 9 & 10 & $\mathrm{Y}$ & $\mathrm{N}$ & EUS/ERCP/IDUS & 92 & $\mathrm{Y}$ & $\mathrm{N}$ & None \\
\hline 10 & 9.4 & $\mathrm{~N}$ & $\mathrm{~N}$ & EUS/ERCP/IDUS & 109 & $\mathrm{Y}$ & $\mathrm{N}$ & None \\
\hline
\end{tabular}

distance needed for balloon advancement above the stone without the use of fluoroscopy. IDUS also allowed for confirmation of stone clearance, with the goal of preventing repeat procedures. IDUS is a safe technique with very few procedure-related complications, and our study also had no known post-procedure complications [10].

A review of 180 patients has shown success rates of up to $90 \%$ for ERCP-NR with an overall morbidity of $15.6 \%$ and 148 healthy infants, and Vohra and colleagues found that same-session EUS in ten pregnant women resulted in ERCP-NR for the six women who had common bile duct stones on EUS $[11,12]$. None of the patients had any immediate procedure-related adverse events, none required a repeat procedure, and none had adverse fetal effects or adverse events at birth.

Similarly, no patients in our study required a repeat procedure, and there were no known maternal or fetal adverse events, suggesting that single-session ERCP-NR with IDUS is a safe and effective method for the treatment of obstructive jaundice and gallstone pancreatitis in pregnant women.

Our study includes an urban safety net hospital with a high Hispanic population (39\%). This population represents a group of women at relatively high risk for stone burden (prevalence of $26.7 \%$ in Mexican Americans and 19.1\% in Hispanics) [13]. Similar to previous studies, ours is limited as it is a single-center study without consistent long-term follow-up. Possible explanations include the retrospective nature of this study, elective pregnancy termination, and insurance changes allowing these women to choose other centers for pre- and post-natal care and delivery.

Various approaches to ERCP-NR as management for symptomatic choledocholithiasis and gallstone pancreatitis have been attempted in pregnant women, and our study confirms positive maternal and fetal outcomes with no known procedural or post-procedural complications [14]. IDUS-guided ERCP-NR provides appropriate biliary imaging without fetal radiation exposure and can be safely and successfully performed in pregnancy.

\section{Authorship and contributorship}

Dr. Kelsey Chen, Dr. Ashwin Ashok, and Dr. Anuj Datta collected and analyzed the data and drafted the manuscript. Dr. Inder Singh and Dr. Michael Fleischman supervised the study and revised the manuscript. Dr. Sonya Reicher and Dr. Viktor Eysselein revised the manuscript for important intellectual content.

\section{References}

1. Sharma SS, Maharshi S (2008) Two stage endoscopic approach for management of choledocholithiasis during pregnancy. J Gastrointestin Liver Dis 17: 183-185. [Crossref]

2. Al-Hashem H, Muralidharan V, Cohen H, Jamidar P (2009) Biliary disease in pregnancy with an emphasis on the role of ERCP. J Clin Gastroenterol 43: 58-62. [Crossref]

3. Fine S, Beirne J, Delgi-Esposti S, Habr F (2014) Continued evidence for safety of endoscopic retrograde cholangiopancreatography during pregnancy. World $J$ Gastrointest Endosc 6: 352-358. [Crossref]

4. Smith I, Gaidhane M, Goode A, Kahaleh M (2013) Safety of endoscopic retrograde cholangiopancreatography in pregnancy: Fluoroscopy time and fetal exposure, does it matter? World J Gastrointest Endosc 5: 148-153. [Crossref]

5. Leo M Di, Arcidiacono P (2013) Fetal radiation exposure: Is monitoring really needed? World J Gastrointest Endosc 5: 366-368. [Crossref]

6. Stimac D, Stimac T (2011) Acute pancreatitis during pregnancy. Eur J Gastroenterol Hepatol 23: 839-844. [Crossref]

7. Agcaoglu O, Ozcinar B, Gok A, Yanar F, Yanar H, Ertekin C, et al. (2013) ERCP without radiation during pregnancy in the minimal invasive world. Arch Gynecol Obstet 288: 1275-1278. [Crossref]

8. Polydorou A, Karapanos K, Vezakis A, Melemeni A, Koutoulidis V, Polymeneas G, et al. (2012) A multimodal approach to acute biliary pancreatitis during pregnancy: A case series. Surg Laparosc Endosc Percutan Tech 22: 429-432. [Crossref]

9. ASGE, Maple JT, Ben-Menachem T, Anderson MA, Appalaneni V, et al. (2010) The 
Datta A (2016) Endoscopic retrograde cholangiopancreatography with intraductal ultrasound in pregnancy without the use of radiation

role of endoscopy in the evaluation of suspected choledocholithiasis. Gastrointest Endosc 71: 1-9.

10. Furukawa T, Oohashi K, Yamao K, Naitoh Y, Hirooka Y, Taki T, et al. (1997) Intraductal ultrasonography of the pancrease: Development and clinical potential. Endoscopy 29: 561-569. [Crossref]

11. Wu W, Faigel D, Sun G, Yang Y (2014) Non-radiation endoscopic retrograde cholangiopancreatography in the management of choledocholithiasis during pregnancy. Dig Endosc 26: 691-700. [Crossref]
12. Vohra S, Holt E, Bhat Y, Kane S, Shah J, Binmoeller K (2014) Successful singlesession endosonography-based endoscopic retrograde cholangiopancreatography without fluoroscopy in pregnant patients with suspected choledocholithiasis: A case series. J Hepatobiliary Pancreat Sci 21: 93-97. [Crossref]

13. Shaffer EA (2006) Epidemiology of gallbladder stone disease. Best Pract Res Clin Gastroenterol 20: 981-996. [Crossref]

14. Driedel D, Stavropoulos S, Iqbal S, Cappell M (2014) Gastrointestinal endoscopy in the pregnant woman. World J Gastrointest Endosc 6: 256-267. [Crossref]

Copyright: ( 02016 Datta A. This is an open-access article distributed under the terms of the Creative Commons Attribution License, which permits unrestricted use, distribution, and reproduction in any medium, provided the original author and source are credited. 